\title{
Application of Tween 80 and Tween 20 for microwave-assisted extraction of oxyresveratrol from mulberry (Morus alba L.) twigs
}

\author{
Raditya Iswandana ${ }^{1}$, Sintha Olisia ${ }^{2}$, Mitha Adriyani², Mahdi Jufri ${ }^{1}$, Abdul Munim²* \\ ${ }^{1}$ Laboratory of Pharmaceutics and Pharmaceutical Technology, Faculty of Pharmacy, Universitas Indonesia, Depok 16424, Indonesia. \\ ${ }^{2}$ Laboratory of Pharmacognosy and Phytochemistry, Faculty of Pharmacy, Universitas Indonesia, Depok 16424, Indonesia.
}

\section{ARTICLE INFO \\ Received on: $15 / 11 / 2019$ \\ Accepted on: 18/01/2020 \\ Available online: 05/03/2020}

\section{Key words:}

Microwave-assisted extraction (MAE), Morus alba, oxyresveratrol, surfactant, Tween 20, Tween 80.

\begin{abstract}
Oxyresveratrol is a polyphenolic compound found in Mulberry (Morus alba L.) twigs and has known as a skinlightening agent. Many methods can be applied to extract oxyresveratrol from Mulberry twigs. This research aimed to optimize the extraction method by using surfactant Tween 80 and Tween 20-based microwave-assisted extraction (MAE). Extraction parameters, including solvent concentration, liquid-solid ratio, and extraction time for oxyresveratrol, were optimized using response surface methodology based on Box-Behnken Design. This research also extracted the oxyresveratrol by maceration, and then the oxyresveratrol content from each extraction method was compared. Oxyresveratrol content was determined using high-performance liquid chromatography (HPLC). For Tween 80 , the optimum condition was obtained at $10.5 \mathrm{mM}, 30: 1 \mathrm{ml} / \mathrm{g}$ liquid-solid ratio, and 10 minutes extraction time. For Tween 20, the optimum condition was obtained at $100 \mathrm{mM}, 40: 1 \mathrm{ml} / \mathrm{g}$ liquid-solid ratio, and 5 minutes extraction time. Oxyresveratrol content was $0.0146 \mathrm{mg} / \mathrm{g}$ dried sample and $0.0172 \mathrm{mg} / \mathrm{g}$ dried sample at the optimum condition of Tween 80 and Tween 20 surfactant, respectively. Meanwhile, the oxyresveratrol content of the maceration method with $96 \%$ ethanol was $1.5704 \mathrm{mg} / \mathrm{g}$ dried sample. In conclusion, these results show that the application of Tween 80 and Tween 20 as solvents for MAE of Oxyresveratrol from mulberry twigs was not fully successful since other extraction conditions should be considered, such as temperature, $\mathrm{pH}$, and microwave energy.
\end{abstract}

\section{INTRODUCTION}

Mulberry plants (Morus alba L., Fig. 1) have been known to have various effects and used as traditional medicine. One of the chemical constitutions from the mulberry plant is oxyresveratrol (Chan et al., 2016). Oxyresveratrol was one of the stilbene groups, which could be found in various types of plants. In the previous study, both in vitro and in vivo results have shown that oxyresveratrol had potential as a tyrosinase enzyme inhibitor, and clinical studies prove that the compound was effective as a lightening agent (Chatsumpun et al., 2016). Accordingly, oxyresveratrol was said to have antioxidant, antiviral, and antibacterial activity (Xu et al., 2014).

\section{"Corresponding Author}

Abdul Munim, Laboratory of Pharmacognosy and Phytochemistry, Faculty of Pharmacy, Universitas Indonesia, Depok 16424, Indonesia.

E-mail:munim@farmasi.ui.ac.id

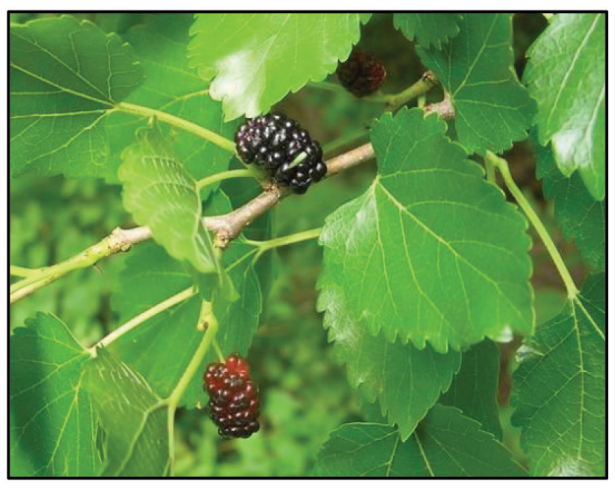

Figure 1. Mulberry plant.

Oxyresveratrol could be found in various parts of mulberry plants, such as roots, stems, and twigs (Soonthornsit et al., 2017). Mulberry twigs were used because of their high oxyresveratrol content compared to other parts, i.e., about $0.12 \%$ 
(Eom et al., 2017). The extraction process was done with ethanol (Lorenz et al., 2003), methanol (Tran et al., 2017), and other organic solvents. The previous study showed that extraction with a maceration method with $96 \%$ ethanol resulted in the highest total resveratrol content, i.e., about $0.34 \%$ (Lorenz et al., 2003).

Surfactants have both hydrophobic and hydrophilic groups that were capable of extracting wide polarity ranged compounds such as polyphenols and could be used to extract and separate polyphenolic compounds such as oxyresveratrol. Surfactants that could be used to extract polyphenols were surfactants with a suitable hydrophilic and lipophilic balance (HLB) value of 15-17 (Sharma et al., 2015). Thus, this study used Tween 20 and Tween 80 surfactants with an HLB value of 16.7 and 15 .

Tween 20 (Polysorbate 20) and Tween 80 (Polysorbate 80) were usually used as an emulsifier. They consist of a polysorbate head group as hydrophilic moiety and an oleoyl chain as the hydrophobic tail. They have low toxicity and cost, biocompatibility, and environmentally friendly (Doost et al., 2018). They have frequently been used to produce essential oil nanoemulsions, to stabilize proteins, and formulation of protein biotherapeutics (Doost et al., 2017; Kerwin, 2008).

The extraction using surfactants and microwaveassisted extraction (MAE) methods was used to accelerate the oxyresveratrol extraction process, and its extraction yield could directly use for cream formulation without having to go through the long process. Accordingly, surfactants used as oxyresveratrol extraction solvent also have many advantages from its toxicity aspect, amount of efficiency, and simpler compared with organic solvents (Płotka-Wasylka et al., 2017).

The MAE method caused direct heating toward the solvent and samples. This method caused soluble ions migration, which increased solvent penetration into the matrix and helped in target compound solubilization (Rostagno and Prado, 2013). This method also caused damage to the plant cell membrane (Ayuningtyas et al., 2017). This study aimed to obtain the optimum extraction condition of oxyresveratrol from mulberry twigs using Tween 80 and Tween 20 as a surfactant with MAE on Response Surface Methodology (RSM) and to compare oxyresveratrol extraction yield using the MAE method with a surfactant as a solvent with maceration with $96 \%$ ethanol as solvent.

\section{MATERIALS AND METHODS}

\section{Materials}

Mulberry (M. alba) twigs dried sample (Bogor, West Java, Indonesia), Tween 80 (KAO Indonesia Chemicals, Indonesia), Tween 20 (KLK Oleo, Malaysia), High-Performance Liquid Chromatography (HPLC) grade acetonitrile (Merck Millipore, Germany), acetic acid (Merck Millipore, Germany), aqua dest, 96\% ethanol pro analysis (Merck Millipore, Germany), HPLC grade methanol (Merck Millipore, Germany), methanol pro analysis (Merck Millipore, Germany), and oxyresveratrol standard (Shanghai Yuanye Bio-Technology, China) were used in this research.

\section{Determination of research method design}

The implementations of this study were divided into some steps, such as research design composition, materials preparation, extraction, and determination of oxyresveratrol content with HPLC. This research was designed by RSM using Design-Expert $^{\circledR}$ 10.0.3 software. The optimization variations can be seen in Table 1. Research data designs were obtained by 17-extraction condition variation (Table 2 ).

\section{Material preparation}

The twigs were obtained from Bogor, Indonesia. Afterward, the twigs went through wet sortation and dried in drying cupboard for seven days. After that, the dried twigs were finely cut and being powdered. The powder was weighted for extraction purposes.

\section{Extraction by MAE method with Tween 80 and Tween 20 (Method 1)}

As much as $1 \mathrm{~g}$ of sample powders were extracted using Tween 80 and Tween 20. Surfactant concentration, solvent-sample ratio, and extraction time were determined using the RSM method (Table 2). The extract, which contained oxyresveratrol, then filtered and centrifuged at 4,000 rpm for 20 minutes until it was separated into two phases, i.e., the residues and the supernatants. The supernatants were collected for the analysis.

\section{Extraction by maceration with $96 \%$ ethanol (Method 2)}

As much as $1 \mathrm{~g}$ of sample powders were extracted with $120 \mathrm{ml}$ of $96 \%$ ethanol for two days at room temperature. The extract was filtered with filter paper. The ethanol filtrate was vaporized using a rotary vacuum evaporator until viscous crude extract was obtained. The extraction yield of viscous crude extract was calculated by the formula below:

$$
\text { Extraction yield }(\%)=\frac{\text { Weight of Extract }}{\text { Weight of Simplicia }} \times 100 \%
$$

\section{Determination of oxyresveratrol content using HPLC}

The determination of oxyresveratrol was done by HPLC (Shimadzu LC-20AT, Japan), C18 Column $(4.6 \times 150 \mathrm{~mm})$ (Shimadzu, Japan). The mobile phase consists of $0.5 \%$ acetic acid solution and acetonitrile $(75: 25) \mathrm{v} / \mathrm{v}$. The flow rate was $1.0 \mathrm{ml} /$ minute. The detector was a UV-Vis detector (Shimadzu SPD-20 A, Japan) with a wavelength of $320 \mathrm{~nm}$.

Table 1. Variables and levels of extraction optimization of Tween 80 and Tween 20.

\begin{tabular}{|c|c|c|c|}
\hline \multicolumn{4}{|c|}{ Extraction with Tween 80} \\
\hline \multirow{2}{*}{ Variables } & \multicolumn{3}{|c|}{ Levels } \\
\hline & -1 & $\mathbf{0}$ & +1 \\
\hline Extraction time (minute) & 5 & 10 & 15 \\
\hline Solvent-sample ratio $(\mathrm{ml} / \mathrm{g})$ & 20 & 30 & 40 \\
\hline Solvent concentration (mM) & 7 & 10.5 & 14 \\
\hline \multicolumn{4}{|c|}{ Extraction with Tween 20} \\
\hline \multirow{2}{*}{ Variables } & \multicolumn{3}{|c|}{ Levels } \\
\hline & -1 & $\mathbf{0}$ & +1 \\
\hline Extraction time (minute) & 1 & 5 & 9 \\
\hline Solvent-sample ratio $(\mathrm{ml} / \mathrm{g})$ & 20 & 30 & 40 \\
\hline Solvent concentration (mM) & 70 & 85 & 100 \\
\hline
\end{tabular}


Table 2. Research data design with RSM of Tween 80 and Tween 20 surfactant.

\begin{tabular}{|c|c|c|c|c|c|c|}
\hline \multirow[t]{2}{*}{$\begin{array}{c}\text { Run } \\
\text { (Variation) }\end{array}$} & \multicolumn{2}{|c|}{$\begin{array}{c}\text { Factor } 1 \\
\text { A: Solvent concentration } \\
(\mathrm{mM})\end{array}$} & \multicolumn{2}{|c|}{$\begin{array}{c}\text { Factor } 2 \\
\text { B: Extraction time } \\
\text { (minute) }\end{array}$} & \multicolumn{2}{|c|}{$\begin{array}{c}\text { Factor } 3 \\
\text { C: Solvent-sample ratio } \\
(\mathrm{ml} / \mathrm{g})\end{array}$} \\
\hline & Tween 80 & Tween 20 & Tween 80 & Tween 20 & Tween 80 & Tween 20 \\
\hline 1 & 10.5 & 85 & 10 & 5 & 30 & 30 \\
\hline 2 & 7 & 70 & 15 & 5 & 30 & 20 \\
\hline 3 & 10.5 & 100 & 5 & 5 & 20 & 20 \\
\hline 4 & 10.5 & 100 & 15 & 5 & 20 & 40 \\
\hline 5 & 14 & 85 & 10 & 5 & 20 & 30 \\
\hline 6 & 10.5 & 70 & 10 & 1 & 30 & 30 \\
\hline 7 & 10.5 & 85 & 15 & 1 & 40 & 40 \\
\hline 8 & 10.5 & 85 & 10 & 9 & 30 & 20 \\
\hline 9 & 7 & 85 & 5 & 1 & 30 & 20 \\
\hline 10 & 7 & 85 & 10 & 9 & 20 & 40 \\
\hline 11 & 7 & 85 & 10 & 5 & 40 & 30 \\
\hline 12 & 10.5 & 100 & 5 & 1 & 40 & 30 \\
\hline 13 & 10.5 & 100 & 10 & 9 & 30 & 30 \\
\hline 14 & 14 & 85 & 5 & 5 & 30 & 30 \\
\hline 15 & 10.5 & 70 & 10 & 9 & 30 & 30 \\
\hline 16 & 14 & 85 & 15 & 5 & 30 & 30 \\
\hline 17 & 14 & 70 & 10 & 5 & 40 & 40 \\
\hline
\end{tabular}

\section{Oxyresveratrol standard solution preparation}

Oxyresveratrol standard solution was prepared until the solution of $1,000 \mu \mathrm{g} / \mathrm{ml}$ concentration was obtained. Afterward, the solution was diluted to $0.3,0.4,0.5,0.6,0.8$, and $0.9 \mu \mathrm{g} / \mathrm{ml}$. Peak areas from chromatograms were used to create the calibration curve and the linear regression equation (Sangsen et al., 2016).

\section{Oxyresveratrol sample solution preparation}

The sample solution was prepared by filtering liquid extract with a micropore membrane. Supernatant from oxyresveratrol liquid extract from Method 1 was filtered with a $0.45 \mu \mathrm{m}$-pore membrane. About $5 \mathrm{mg}$ viscous crude extract from Method 2 was diluted in $5 \mathrm{ml}$ methanol until a solution of 1,000 $\mu \mathrm{g} / \mathrm{ml}$ was obtained. Afterward, the solution was diluted until 100 $\mu \mathrm{g} / \mathrm{ml}$ and filtered with a $0.45 \mu \mathrm{m}$-pore membrane.

\section{Scanning electron microscope (SEM)}

Mulberry twigs powder (before and after extraction) was examined by using SEM. This characterization was needed to learn about the morphology changes of the cell wall during the extraction process with Tween 80 or Tween 20 -MAE and $96 \%$ ethanol-maceration method.

\section{Data analysis}

HPLC data result from all samples was processed by using Design Expert ${ }^{\circledR}$ 10.0.3 software with the RSM method to determine the optimum condition from various combinations of variables in the extraction process.

\section{RESULTS AND DISCUSSION}

\section{Extraction}

Extraction was done by two methods, i.e., MAE method with Tween 80 and Tween 20 as solvent (Method 1) and maceration method with $96 \%$ ethanol as solvent (Method 2). A preliminary study was done beforehand to determine the variable values of the extraction condition in Method 1. Extraction was done by two methods, i.e., MAE method with Tween 80 and Tween 20 as solvent (Method $1 \mathrm{a}$ and $1 \mathrm{~b}$ ) and maceration method with $96 \%$ ethanol as solvent (Method 2). Orientation was done first to determine the variable values of the extraction condition in Method 1.

\section{MAE method with Tween 80 extraction (Method 1a)}

In Method 1a, the analyzed factors in this method were solvent concentration, solvent-sample ratio, and the extraction time (Rostagno and Prado, 2013). Surfactant solvent concentration was of 7,10.5, and $14 \mathrm{mM}$ and for solvent-sample ratio was 20:1, 30:1, and 40:1 ml/g (Lu et al., 2017). The values used for each factor were determined based on the result of the preliminary study from previous related studies (Koyu et al., 2017). For extraction time, the time point was determined at 5, 10, and 15 minutes. After the lowest, middle, and highest values from each factor were determined, the variation of extraction condition was obtained from 17 variations. The extraction was done with the MAE method. All variations of the extraction condition can be seen in Table 2.

\section{MAE method with Tween 20 extraction (Method 1b)}

In Method 1b, surfactant solvent concentration was 70, 85 , and $100 \mathrm{mM}$ and for solvent-sample ratio was 20:1, 30:1, and $40: 1 \mathrm{ml} / \mathrm{g}$. The values used for each factor were determined based on the result of the preliminary study from previous related studies (Koyu et al., 2017). For extraction time, the time point was determined at 1, 5, and 9 minutes. After the lowest, middle, and highest values from each factor were determined, the variation of extraction condition was obtained from 17 variations. The 
extraction was done with the MAE method. All variations of the extraction condition can be seen in Table 2 .

\section{Maceration method with $96 \%$ ethanol extraction (Method 2)}

The extraction yield obtained from the maceration method with $96 \%$ ethanol was $3.0 \%$. The extraction yield was diluted in methanol and analyzed using HPLC.

\section{Determination of oxyresveratrol content with HPLC}

The peak area obtained from each concentration analysis was used to create a correlation curve between standard concentrations and peak areas. After the linear regression equation was obtained from the calibration curve, the oxyresveratrol content from Methods 1 and 2 was determined. The retention time was determined based on the time from the calibration curve. The calculation shows at 8 minutes (Fig. 2a). Thus, the peak that appeared around 8 minutes in the sample chromatogram was determined as oxyresveratrol (Fig. $2 b$ and c).

In Method 1, oxyresveratrol content was determined by calculating the $x$ values from the linear regression equation
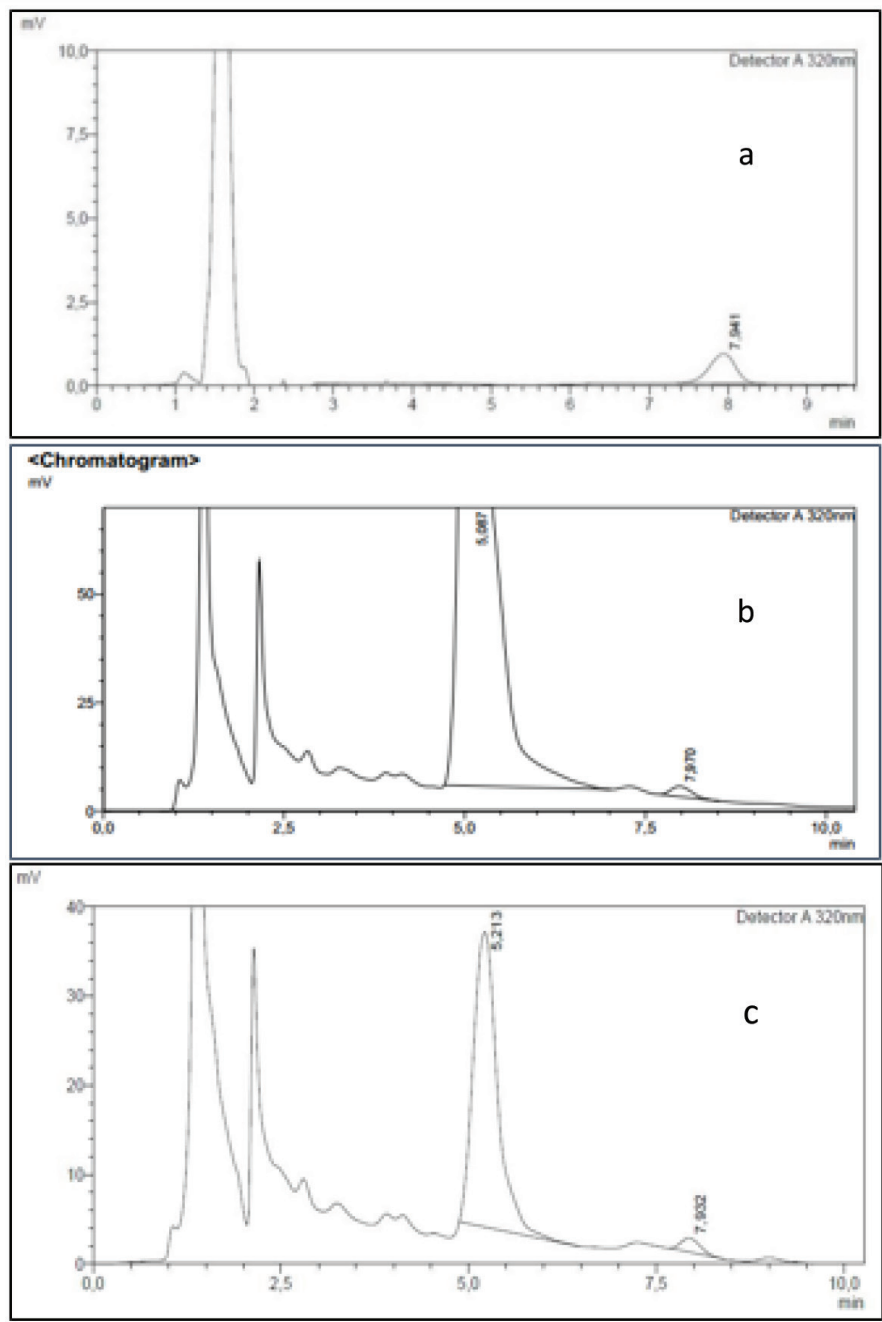

Figure 2. Oxyresveratrol retention time: (a) standard solution at $0.3 \mu \mathrm{g} / \mathrm{ml}$ concentration, (b) oxyresveratrol chromatogram of run 8 sample solution in Tween 80 solvent, and (c) oxyresveratrol chromatogram of variation 1 sample solution in Tween 20. obtained from the standard calibration curve. The values were obtained based on oxyresveratrol peak area value from the sample solution. Oxyresveratrol content was in $\mathrm{mg} / \mathrm{g}$ sample unit. These results are described in Figures 3 and 4.

Method 1a: In Figure 3, the highest oxyresveratrol content was obtained at variation $6(0.0146 \mathrm{mg} / \mathrm{g}$ dried sample $)$ with $10.5 \mathrm{M}$ solvent concentration, $30: 1 \mathrm{ml} / \mathrm{g}$ solvent-sample ratio, and 10 minutes extraction time. Meanwhile, the lowest oxyresveratrol content was obtained at variation $3(0.0055 \mathrm{mg} / \mathrm{g}$ dried sample) with $10.5 \mathrm{M}$ solvent concentration, $20: 1 \mathrm{ml} / \mathrm{g}$ solvent-sample ratio, and $5 \mathrm{~min}$ extraction time.

Method 1b: In Figure 4, oxyresveratrol content from variation 4 had the highest content of $0.0172 \mathrm{mg} / \mathrm{g}$ dried sample with $100 \mathrm{mM}$ solvent concentration, $40: 1 \mathrm{ml} / \mathrm{g}$ solvent-sample ratio, and 5 minutes extraction time.

Method 2. The result from the maceration method was $1.5704 \mathrm{mg} / \mathrm{g}$ dried sample. This result was higher compared to the result of the optimum condition of MAE with Tween 80 and Tween 20 .

The highest oxyresveratrol content from Method 1a was obtained from variation 6 with a $10.5 \mathrm{M}$ solvent concentration, $30: 1 \mathrm{ml} / \mathrm{g}$ solvent-sample ratio, and 10 minutes extraction time. The highest oxyresveratrol content was obtained at 10 minutes of extraction and decreased after 10-15 minutes. This condition proved that the equilibrium of the compound release from the plant matrix occurred in 10 minutes. The use of a high solvent-sample ratio could increase the probability of contact with the extraction

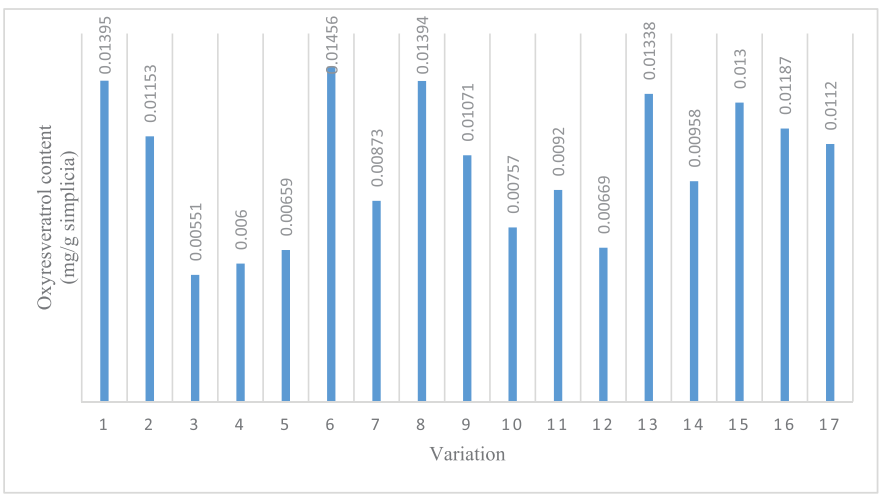

Figure 3. Result of oxyresveratrol content for every sample variation of Tween 80 .

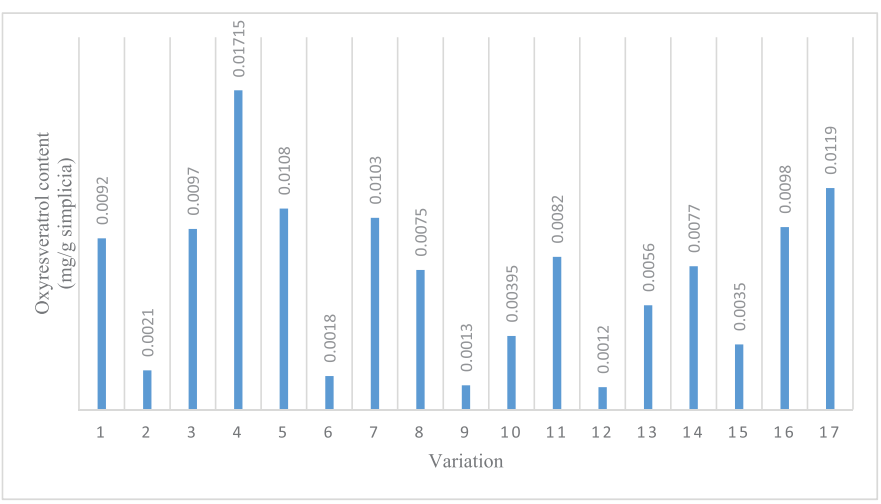

Figure 4. Oxyresveratrol content of every sample variation of Tween 20 . 
solvent. It gave a higher compound release level in a solvent. However, the extracted compound would not increase any more after the point of equilibrium was achieved (Tan et al., 2011). The equilibrium of the solvent-sample ratio of this study was $30 \mathrm{ml} / \mathrm{g}$.

The lowest oxyresveratrol content from Method $1 \mathrm{~b}$ was obtained from variation 12 , and the content was 0.0012 $\mathrm{mg} / \mathrm{g}$ dried sample, with $100 \mathrm{mM}$ solvent concentration, 30:1 $\mathrm{ml} / \mathrm{g}$ solvent-sample ratio, and 1 minute extraction time. The highest oxyresveratrol content from variation 4 was caused by the high solvent concentration of $100 \mathrm{mM}$, which resulted in a quite high oxyresveratrol content on the orientation process, and an extraction time of 5 minutes. The low result of variation 12 was caused by a quick extraction time, which was only 1 minute. It can cause the extraction process incomplete, even though the value of solvent concentration used was optimum compared to another condition.

Based on the content determination of Method 2, the result of oxyresveratrol content was higher compared to the result of the optimum condition of Method $1 \mathrm{a}$ and $1 \mathrm{~b}$. It was related to the maceration method mechanism and the contact time of the solvent and sample in the maceration. The submersion mechanism in the maceration method could soften and destroy plants' cell walls. Thus, it made the solvent easily diluting the bioactive compound from plants. The longer contact time between the solvent and the sample also affects the bioactive compound extracted from the extraction process (Azwanida, 2015). Longer contact time between solvent and sample could increase mass transfer that occurred in the extraction process (Tan et al., 2013).

Nevertheless, Method 1 had some advantages to shorten the steps in the process of drug formulation because the obtained extract could be used directly for formulation. Accordingly, this extraction method was also made the extraction time to be more efficient. However, this extraction had one disadvantage that it needs more materials than conventional does.

\section{Optimum condition determination with RSM}

The optimum extraction condition was determined by inputting the oxyresveratrol average content as a response in the $y$-axis against variables used in this study as the $x$-axis. Data were analyzed using multivariate regression analysis. The regression model was obtained to predict the optimum condition with Method la by using the following equation:

$$
\begin{aligned}
Y= & 0.014-2.875 \times 10^{-5} X_{1}+7.050 \times 10^{-4} X_{2}+1.269 \\
& \times 10^{-3} X_{3}+3.675 \times 10^{-4} X_{1} X_{2}+7.450 \times 10^{-4} X_{1} X_{3} \\
& +3.875 \times 10^{-4} X_{2} X_{3}-4.680 \times 10^{-4} X_{1}^{2}-2.376 \times 10^{-3} X_{2}^{2} \\
& -4.658 \times 10^{-3} X_{3}^{2}
\end{aligned}
$$

wherein $Y$ value is the average value of oxyresveratrol content, $X_{1}$ is A factor (Tween 80 concentration), $X_{2}$ is B factor (extraction time), and $X_{3}$ is $\mathrm{C}$ factor (solvent-sample ratio). The recommended model was the quadratic model because this model had $p$-value $<0.05$, which showed that the interaction between factors in this model was quite significant. The $R^{2}$ value for this response was 0.9825 , which means that this response surface model had enough accuracy and showed the adequacy of the regression model applied.
Then, the optimum condition determination of Method $1 \mathrm{~b}$, based on the analysis result, was obtained at 5 minutes extraction time, $40: 1 \mathrm{ml} / \mathrm{g}$ solvent-sample ratio, and $100 \mathrm{mM}$ solvent concentration, which corresponded with variation 4 of extraction sample. Analysis result was also obtained regression linear equation, which predicted oxyresveratrol content value. The acquired equation is as follows:

$$
\begin{aligned}
Y= & 0.00994-0.0000375 X_{1}+0.004312 X_{2}+0.003212 X_{\mathrm{a}} \\
& -0.00313 X_{1} X_{2}+0.000675 X_{1} X_{\mathrm{a}}-0.005182 X_{1}^{2} \\
& -0.0007322 X_{3}^{2}-0.00295 X_{1}^{2} X_{2}-0.002837 X_{1}^{2} X_{\mathrm{a}} \\
& +0.001562 X_{1} X_{3}^{2}
\end{aligned}
$$

The above equation had an $R^{2}$ value of 0.9275 , wherein $Y$ shows oxyresveratrol content value, $X_{1}$ is A factor (extraction time), $X_{2}$ is B factor (solvent-sample ratio), and $X_{3}$ is $\mathrm{C}$ factor (solvent concentration). Based on the RSM analysis result, $F$ value for lack of fit $(p>0.05)$ was 0.0752 ; this shows that the probability of some errors was insignificant. Afterward, the $F$ value from this model $(p<0.05)$ was 0.0107 . It shows that the correlation or interaction between the combined factors used in the equation had a significant effect on the resulted response, which was the obtained oxyresveratrol content.

The result of the response surface graph obtained can be seen in Figures 5 and 6. For Method 1a, the optimum result was obtained in $10.5 \mathrm{mmol} / \mathrm{l}$ concentration. The concentration effect was linked with solvent viscosity that affected its capability in penetrating itself into the cell membrane. The higher the viscosity, the lower the solvent capability to extract the target compound from the matrix of the sample (Rostagno and Prado, 2013). In this study, it was reported that 10 minutes was the optimum time to extract oxyresveratrol.

Another factor, which affected the extraction process in this study, was a solvent-sample ratio. The large solventsample ratio could cause the extraction process to be ineffective, and a small solvent-sample ratio could cause an incomplete extraction process (Ahmad et al., 2017). Based on this study, in Method 1a, the optimum condition was variation $6(10.5$ $\mathrm{mmol} / 1$ surfactant concentration, $30: 1 \mathrm{ml} / \mathrm{g}$ the solvent-sample ratio, and 10 minutes extraction time) with desirability index of 0.977 . This was done by looking at the desirability index that ranged from 0 to 1 . If the value was close to number 1 , then the conditions were closer to the optimum condition. The analysis condition of Method $1 \mathrm{~b}$ was variation 4 , which conditions were 5 minutes of extraction time, $40: 1 \mathrm{ml} / \mathrm{g}$ solvent-sample ratio, and $100 \mathrm{mM}$ solvent concentration. The desirability index value obtained was 0.993 .

\section{Cell wall damage effect on extraction with SEM}

To study the cell wall damage during extraction, the mulberry twigs powder before extraction and its residue after extraction were checked with SEM. Based on Figure 7, the cell wall structure shows good integrity before extraction (Fig. 7a), but after maceration method extraction with $96 \%$ ethanol, the cell wall went through some damages (Fig. 7b). The damages on samples of the maceration method occurred because there was a damage mechanism on the cell wall caused by the submersion process 


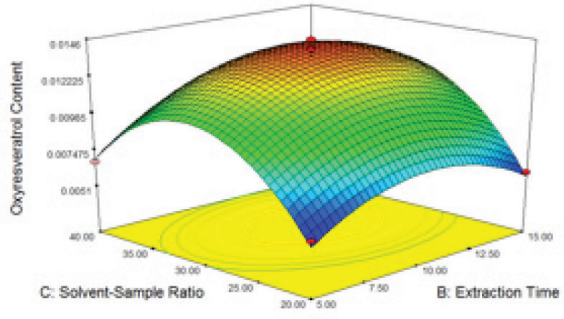

(a)

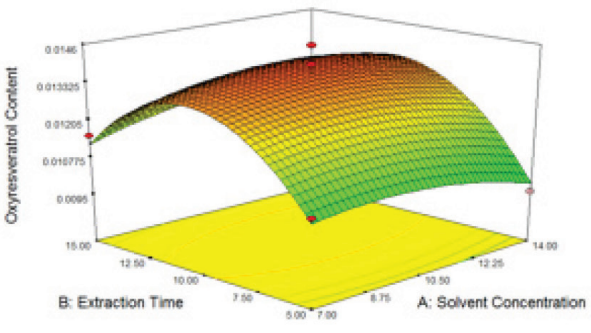

(b)

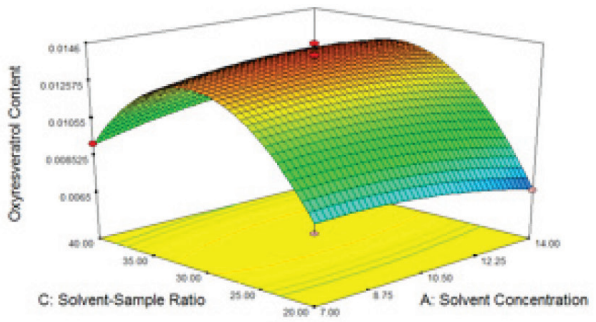

(c)

Figure 5. Response surface graph of two factors relationship of (a) concentration-time, (b) concentration-solventsample ratio, and (c) time-solvent-sample ratio.

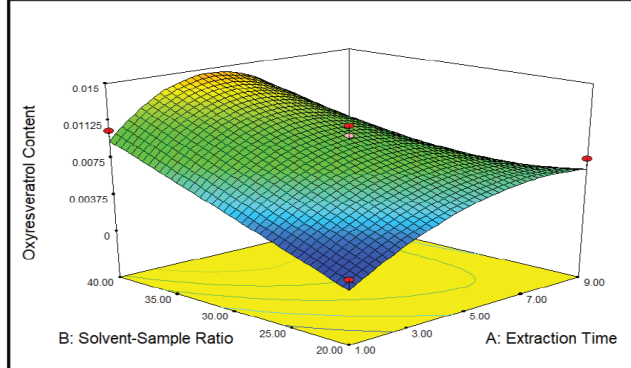

(a)

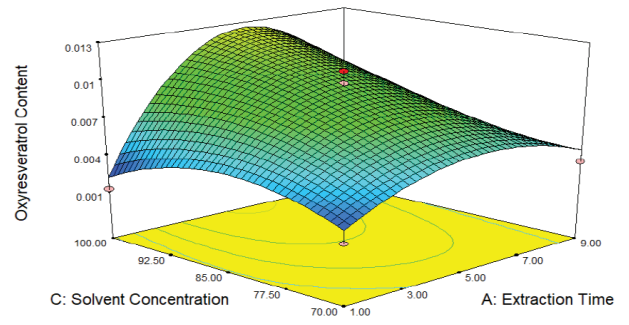

(b)

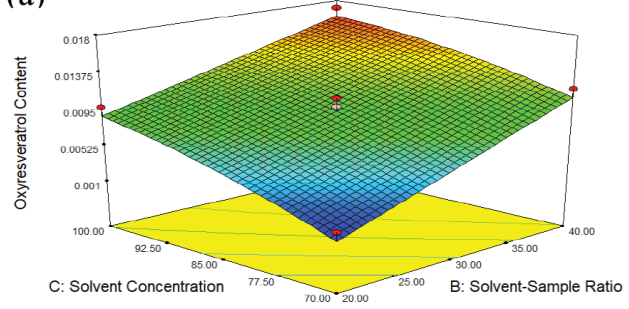

(c)

Figure 6. Response surface graph of two factors relationship of (a) solvent-sample ratio - time, (b) concentrationtime, and (c) concentration - solvent-sample ratio.

and agitation in the maceration process (16). From Method 1, the cell wall structure did not undergo more severe damage than with Method 2 (Fig. 7c and d). In this study, it was known that microwave application in the MAE method could affect cell structure because there were immediate changes in temperature and internal pressure (Zhou and Liu, 2006). Therefore, in this case, Tween 80 did not show any effect on the cell wall damage, but the extraction mechanism of the MAE method could make Tween 80 surfactant easily penetrates and dissolves the secondary metabolite from mulberry twigs. 


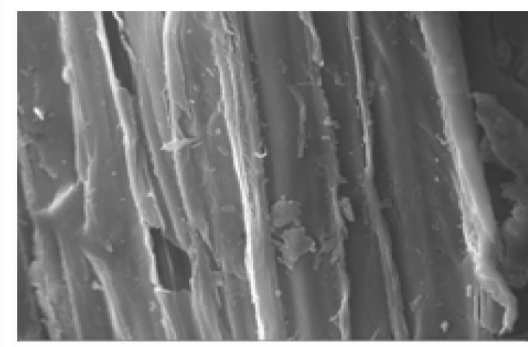

(a)

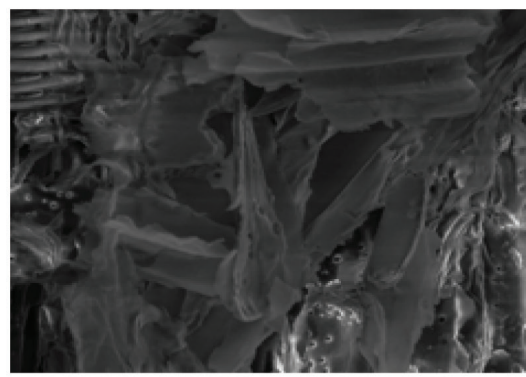

(c)

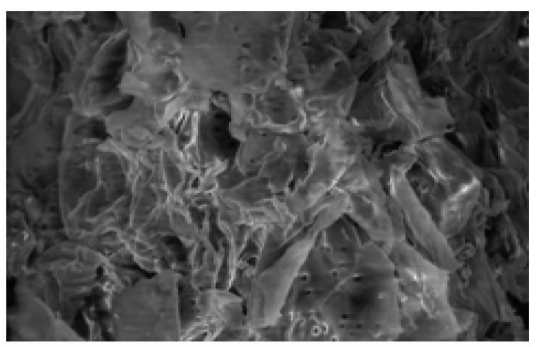

(b)

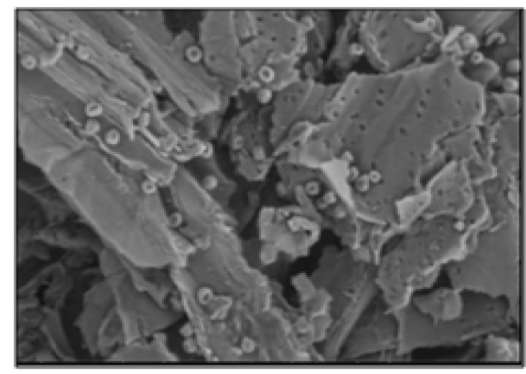

(d)

Figure 7. Scanning electron microscope result from mulberry twigs: (a) before extraction, (b) after maceration method extraction with $96 \%$ ethanol, (c) after MAE method extraction with Tween 80, and (d) after MAE method extraction with Tween 20.

\section{CONCLUSION}

The optimum extraction condition of oxyresveratrol from mulberry twigs by using the MAE-RSM-based method with Tween 80 was obtained at $10.5 \mathrm{mM}, 30: 1 \mathrm{ml} / \mathrm{g}$ solventsample ratio, and 10 minutes extraction time. The optimum extraction condition of oxyresveratrol from $M$. alba twigs of the MAE method with Tween 20 was obtained at $100 \mathrm{mM}$, $40: 1 \mathrm{ml} / \mathrm{g}$ solvent-sample ratio, and 5 minutes extraction time. Oxyresveratrol content that gained at the optimum condition of Tween 80 and Tween 20 was lower than oxyresveratrol content from maceration with $96 \%$ ethanol. Oxyresveratrol content was $0.0146 \mathrm{mg} / \mathrm{g}$ dried sample, and $0.0172 \mathrm{mg} / \mathrm{g}$ dried sample at the optimum condition of Tween 80 and Tween 20 surfactant, respectively. Meanwhile, the oxyresveratrol content of the maceration method with $96 \%$ ethanol was $1.5704 \mathrm{mg} / \mathrm{g}$ dried sample. Therefore, additional studies should be undertaken to optimize other parameters, such as temperature, $\mathrm{pH}$, and microwave energy, which affect the extraction of oxyresveratrol content.

\section{ACKNOWLEDGMENTS}

The authors gratefully acknowledge the funding from Directorate of Research and Community Engagement Universitas Indonesia, via Hibah Publikasi Terindeks Internasional untuk Tugas Akhir (PITTA) 2018 supporting this work.

\section{CONFLICT OF INTEREST}

The authors have no conflict of interest to declare.

\section{REFERENCES}

Ahmad I, Yanuar A, Mulia K, Mun'im A. Optimization of ionic liquid-based microwave-assisted extraction of polyphenolic content from Peperomia pellucida (L) Kunth using response surface methodology. Asian Pac J Trop Biomed, 2017; 7(7):660-5.

Ayuningtyas IN, Rahmawati M, Sutriyo, Mun'im A. Optimization of ionic liquid-based microwave assisted extraction to obtain trans-resveratrol from Gnetum gnemon L. seeds. J Young Pharm, 2017; 9(4):446-51.

Azwanida NN. Review on the extraction methods use in medicinal plants, principle, strength and limitation. Med Aromat Plants, 2015; 4(3):3-8.

Chan EW, Lye PY, Wong SK. Phytochemistry, pharmacology, and clinical trials of Morus alba. Chin J Nat Med, 2016; 14(1):17-30.

Chatsumpun N, Chuanasa T, Sritularak B, Lipipun V, Jongbunprasert V, Ruchirawat S, Ploypradith P, Likhitwitayawuid K. Oxyresveratrol: structural modification and evaluation of biological activities. Molecules, 2016; 21(4):489.

Doost AS, Dewettinck K, Devlieghere F, Van der Meeren P. Influence of non-ionic emulsifier type on the stability of cinnamaldehyde nanoemulsions: a comparison of polysorbate 80 and hydrophobically modified inulin. Food Chem, 2018; 258:237-44.

Doost AS, Sinnaeve D, De Neve L, Van der Meeren P. Influence of non-ionic surfactant type on the salt sensitivity of oregano oil-in-water emulsions. Colloid Surface A Physicochem Eng Aspects, 2017; 525:38-48.

Eom JH, Phuong T, Vu D, Cai L, Zhao Y, Li HX, Kang JS. Development of HPLC method for differentiation of three parts of mulberry tree. Anal Sci Tech, 2017; 30:130-7.

Kerwin BA. Polysorbates 20 and 80 used in the formulation of protein biotherapeutics: structure and degradation pathways. J Pharm Sci, 2008; 97:2924-35. 
Koyu H, Kazan A, Ozturk T, Yesil-Celiktas O, Haznedaroglu M. Optimizing subcritical water extraction of Morus nigra L. fruits for maximization of tyrosinase inhibitory activity. J Supercrit Fluids, 2017; $127: 15-22$.

Lorenz P, Roychowdhury S, Engelmann M, Wolf G, Horn TFW. Oxyresveratrol and resveratrol are potent antioxidants and free radical scavengers: effect on nitrosative and oxidative stress derived from microglial cells. Nitric Oxide, 2003; 9(2):64-76.

Lu H, Jia Y, Peng Y, Yu Y, Sun S, Yue M, Pan M, Zeng L, Xu L. Oxyresveratrol, a stilbene compound from Morus alba L. twig extract active against Trichophyton rubrum. Phytother Res, 2017; 31(12):1842-8.

Płotka-Wasylka J, Rutkowska M, Owczarek K, Tobiszewski M, Namieśnik J. Extraction with environmentally friendly solvents. Trends Anal Chem, 2017; 91:12-25.

Rostagno MA, Prado JM. Natural product extraction: principles and application. RSC Publishing, Cambridge, UK, 2013.

Sangsen Y, Wiwattanawongsa K, Likhitwitayawuid K, Sritularak B, Graidist P, Wiwattanapatapee R. Influence of surfactants in self-microemulsifying formulations on enhancing oral bioavailability of oxyresveratrol: studies in caco-2 cells and in vivo. 2016; 498(1-2):294-303.

Sharma S, Kori S, Parmar A. Surfactant mediated extraction of total phenolic contents (TPC) and antioxidants from fruits juices. Food Chem, 2015; 185:284-8.

Soonthornsit N, Pitaksutheepong C, Hemstapat W, Utaisincharoen P, Pitaksuteepong T. In vitro anti-inflammatory activity of Morus alba L. stem extract in LPS-stimulated RAW 264.7 cells. Evid Based Complementary Altern Med, 2017; 2017:1-8.
Tan M, Tan C, Ho C. Effects of extraction solvent system, time and temperature on total phenolic content of henna (Lawsonia inermis) stems. Int Food Res J, 2013; 20(6):3117-23.

Tan PW, Tan CP, Ho CW. Antioxidant properties: Effects of solid-to-solvent ratio on antioxidant compounds and capacities of pegagan (Centella asiatica). Int Food Res J, 2011; 18:557-62.

Tran HNK, Nguyen VT, Kim JA, Rho SS, Woo MH, Choi JS, Lee JH, Min BS. Anti-inflammatory activities of compounds from twigs of Morus alba. Fitoterapia, 2017; 120:17-24.

Xu L, Liu C, Xiang W, Chen H, Qin X, Huang X. Advances in the study of oxyresveratrol. Int J Pharmacol, 2014; 10(1):44-54.

Zhou H, Liu C. Microwave-assisted extraction of solanesol from tobacco leaves. J Chromatogr A, 2006; 1129(1):135-9.

\section{How to cite this article:}

Iswandana R, Olisia S, Adriyani M, Jufri M, Munim A. Application of Tween 80 and Tween 20 for microwave-assisted extraction of oxyresveratrol from mulberry (Morus alba L.) twigs. J Appl Pharm Sci, 2020; 10(03):093-100. 